\title{
Translations of volcanological terms: cross-cultural standards for teaching, communication, and reporting
}

\author{
Andrew J. L. Harris ${ }^{1}$ - Alexander Belousov ${ }^{2} \cdot$ Sonia Calvari $^{3}$.

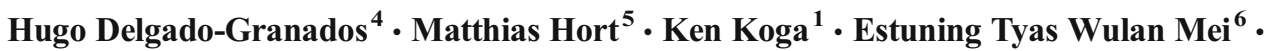 \\ Agung Harijoko $^{6}$. José Pacheco ${ }^{7}$. Jean-Marie Prival ${ }^{1}$. Carmen Solana ${ }^{8}$. \\ Porvaldur Pórðarson ${ }^{9} \cdot$ Jean-Claude Thouret ${ }^{1} \cdot$ Benjamin van Wyk de Vries ${ }^{1}$
}

Received: 15 March 2017 / Accepted: 20 June 2017

(C) Springer-Verlag GmbH Germany 2017

\begin{abstract}
When teaching at a non-English language university, we often argue that because English is the international language, students need to become familiar with English terms, even if the bulk of the class is in the native language. However, to make the meaning of the terms clear, a translation into the native language is always useful. Correct translation of terminology is even more crucial for emergency managers and decision makers who can be confronted with a confusing and inconsistently applied mix of terminology. Thus, it is imperative to have a translation that appropriately converts the meaning of a term, while being grammatically and lexicologically correct, before the need for use. If terms are not consistently defined across all languages following industry standards and norms, what one person believes to be a $d o g$, to another is a cat. However, definitions and translations of English scientific and technical terms are not always available, and language is constantly evolving. We live and work in an international world where English is the common language of multi-cultural exchange. As a result, while finding the correct
\end{abstract}

Editorial responsibility: P-S Ross

Andrew J. L. Harris

a.harris@opgc.univ-bpclermont.fr

1 CNRS, OPGC et IRD, Université Clermont Auvergne, Campus Les Cézeaux, 6 avenue Blaise Pascal, Aubière 63178, France

2 Institute of Volcanology and Seismology, Piip Boulevard 9, Petropavlovsk-Kamchatsky, Russia 683006

3 Istituto Nazionale di Geofisica e Vulcanologia Sezione di Catania (INGV-Catania), Piazza Roma 2, 95125 Catania, Italia

4 Departamento de Vulcanología, Instituto de Geofísica, Universidad Nacional Autónoma de México, CU, Coyoacán, 04510 Mexico City, Mexico translation can be difficult because we are too used to the English language terms, translated equivalents that are available may not have been through the peer review process. We have explored this issue by discussing grammatically and lexicologically correct French, German, Icelandic, Indonesian, Italian, Portuguese, Russian, Spanish, and Japanese versions for terms involved in communicating effusive eruption intensity.

Keywords Volcanology Communication · Teaching · Translation

\section{Introduction}

Due to the needs of internationalization and globalization in science and education (e.g., Knight 1994; Gacel-Ávila 2005), a lack of peer-reviewed, industry-standard term translation of formal nomenclature is becoming an increasing problem. This
5 Institut für Geophysik, Universität Hamburg, Bundesstrasse 55, D-20146 Hamburg, Germany

6 Faculty of Geography, Universitas Gadjah Mada, Yogyakarta 55281, Indonesia

7 Edifício do Complexo Científico, Instituto de Investigação em Vulcanologia e Avaliação de Riscos/Universidade dos Açores, Rua da Mãe de Deus, $3^{\circ}$ Andar-Ala Sul, 9500-321 Ponta Delgada, Açores, Portugal

8 School of Earth and Environmental Sciences, University of Portsmouth, Burnaby Building, Portsmouth PO1 3QL, UK

9 School of Engineering and Natural Sciences - Faculty of Earth Sciences, University of Iceland, Askja/N-141, 101, Reykjavik, Iceland 